Research Article

\title{
Response Characteristics of Dynamic Torque for Wet Clutch Engagement: A Numerical and Experimental Study
}

\author{
Zhigang Zhang $\mathbb{D}^{1,2}$ Ling Zou $\mathbb{D}^{1},{ }^{1}$ Hang Liu $\mathbb{D},{ }^{1}$ Jin Feng $\mathbb{D}^{1},{ }^{1}$ and Zhige Chen $\mathbb{D}^{1}$ \\ ${ }^{1}$ Key Laboratory of Advanced Manufacturing Technology for Automobile Parts, Ministry of Education, \\ Chongqing University of Technology, Chongqing 400054, China \\ ${ }^{2}$ Ningbo Shenglong Group Co., Ltd., Ningbo 315104, China \\ Correspondence should be addressed to Zhigang Zhang; zhangzhigang@cqut.edu.cn
}

Received 6 February 2021; Revised 28 April 2021; Accepted 8 May 2021; Published 18 May 2021

Academic Editor: Dario Richiedei

Copyright (c) 2021 Zhigang Zhang et al. This is an open access article distributed under the Creative Commons Attribution License, which permits unrestricted use, distribution, and reproduction in any medium, provided the original work is properly cited.

To determine the factors affecting the dynamic transmitted torque response characteristics of the wet clutch, the oil film pressure, the asperity contact pressure, the applied pressure, and the dynamic transmitted torque model were established, using the fourthorder Runge-Kutta numerical method to couple the oil film thickness and the speed difference to obtain the change curve of the joint pressure and the transmitted torque. The established model was used to study the influence of the pressure hysteresis time, lubricant viscosity, friction lining permeability, friction pair equivalent elastic modulus, and surface combined roughness RMS on the dynamic transmitted torque response during the wet clutch engagement. The results indicate that the longer the pressure hysteresis time, the smaller the permeability of the friction lining, the smaller the equivalent elastic modulus, the greater surface combined roughness RMS, the more delayed the response of the transmitted torque, and the smaller the level of jerk of the wet clutch engagement. Also, the lower the lubricant viscosity, the greater the permeability of the friction lining, and the smaller the equivalent elastic modulus is and the greater surface combined roughness RMS is, the more sensitive the transmitted torque response is to pressure response changes.

\section{Introduction}

As a core component of vehicle transmission systems, the wet clutch plays a critical role in vehicle starting and gear shifting processes. It is widely used in premium sedans, heavy-duty vehicles, and crawler vehicles [1]. In the working process of the wet clutch, the dynamic transmission of torque highly depends on the hydraulic pressure acting on the piston for compression of the separator plate and the friction disk of friction pairs. Studying the regulation of the transmitted torque during wet clutch engagement significantly affects the detail and optimization of the developed control strategy, which further determines the starting stability of the vehicle and the sensing of frustration during gear shifting. Concurrently, it significantly impacts the sliding friction power of the wet clutch during vehicle starting and gear shifting. The variation in dynamic transmitted torque of the wet clutch mainly depends on its torque response characteristics [2]. Consequently, the effects of various factors on the dynamic transmitted torque response of the wet clutch are analyzed on the basis of the friction transmission mechanism of the wet clutch, which is of great significance for obtaining the optimal wet clutch control strategy.

Existing domestic and international research on the wet clutch has mainly focused on the modeling of wet clutch engagement characteristics, analysis of thermal characteristics, and control optimization. Gao et al. [3] performed experiments to investigate the surface asperity height distribution model of the paper-based friction disk and subsequently modeled and simulated the wet clutch engagement characteristics via a surface asperity height distribution model. [4] A three-dimensional finite element model and a heat conduction model of the friction pair were established, in which the influence of the groove was considered. Liu et al. [1] established a mathematical model of the wet clutch 
engagement by analyzing the engagement of the wet clutch, applying the one-dimensional average Reynolds equation and the rough surface elastic contact model. The effect of wet clutch engagement pressure on viscous torque, rough friction torque, and transmitted torque during the engagement is studied. Yu et al. [5] studied the friction torque characteristics of a paper-based wet clutch based on the modified Reynolds equation. Reference [6] discussed the influence of engagement pressure, lubricating oil working temperature, friction coefficient, and other factors on the transmitted torque of the wet clutch during the working engagement. Chen [7] did clutch engagement tests under different working conditions and studied the influence of engagement oil pressure on speed and the influence of engagement oil pressure and speed on torque. Chen studied the torque transmission characteristics of a clutch with a single friction pair and proposed the concept of equivalent friction coefficient. Simulation results show that increasing viscosity or decreasing surface roughness can lead to smooth incremental torque. Increasing control oil pressure can reduce engagement time, but the peak of power loss will increase. Decreasing Yong's modulus can delay response of asperity contact torque and increase engagement time [8].

Miyagawa et al. [9] conducted heat-fluid-solid coupling analysis to study the wet clutch engagement characteristics, developed the wet clutch engagement characteristic model, and studied the influence of groove type on the engagement characteristics of friction pairs. Reference [10] has tried to study the torque transmission characteristics in radial magnetorheological (MR) clutch discs with different groove profiles. Jang et al. [4] developed a thermodynamic model to analyze the torque response of a wet clutch with different groove patterns and showed that thermal effects critically impact the engagement time and torque response. Reference [11] established a multiphysics coupling clutch thermodynamic model, analyzed the generation and change mechanism of viscous torque and contact torque during clutch engagement, and studied the influence of lubricating oil temperature on friction torque characteristics. Depratere et al. [12] applied a bilevel iterative learning control strategy to control wet clutch engagement in an optimal manner and observed that the engagement quality was adequate. Reference [13] proposed a new adaptive control method of clutch torque, which mainly focused on the relationship between dry clutch and actuator piston pressure and clutch torque. However, response characteristics of torque in wet clutch engagement from the standpoint of the friction transmission mechanism of the wet clutch have scarcely been investigated.

In this study, on the basis of the analysis of the wet clutch friction transmission mechanism, a dynamic transmitted torque model of the wet clutch is proposed, and the factors influencing the torque response characteristics of the wet clutch are analyzed via numerical simulations and experimental methods.

\section{Friction Transmission Mechanism of Wet Clutch}

According to the mechanisms of applied force and transmitted torque of the wet clutch, the wet clutch engagement process can be divided into three stages [14]: the fluid squeezing stage, boundary lubrication stage, and mechanical contact stage. In the fluid squeezing stage, transmitted torque is composed of hydrodynamic torque of the automatic transmission fluid (ATF) oil film. In the boundary lubrication stage, the transmitted torque is composed of hydrodynamic torque of the ATF oil film and the asperity contact torque of friction pairs. With wet clutch engagement, contact pressure and friction torque of asperities gradually play a dominant role. In the mechanical contact stage, the transmitted torque is only composed of asperity friction torque. The friction transmission mechanism in wet clutch engagement is modeled as follows.

2.1. Model of Oil Film Pressure. Wet clutch engagement can be simplified as per the physical model shown in Figure 1. Friction pairs are filled with lubricant before wet clutch engagement, and the friction disk and separator plate are separated by the oil film. The angular velocity of friction disk and separator plate are $\omega_{2}$ and $\omega_{1}$, respectively; then, friction pairs are compressed gradually via the applied pressure $P_{s}$. Combined with the axial symmetric characteristics of the wet clutch friction pairs, the governing equation of the force supported by the oil film in cylindrical coordinate system is derived using the Patir-Cheng average Reynolds equation $[15,16]$,

$$
\frac{\mathrm{d}}{\mathrm{d} r}\left[r \varphi_{r}\left(h^{3}+12 \Phi d\right) \frac{\mathrm{d} P_{h}}{\mathrm{~d} r}\right]=12 \eta \mathrm{r} \frac{\mathrm{d} \bar{h}_{T}}{\mathrm{~d} t},
$$

where $\varphi_{r}$ is the radial flow factor, $h$ is the film thickness of the oil, $\Phi$ is the permeability of the friction lining, $d$ is the thickness of the friction lining, $P_{h}$ is the average pressure of the oil film, $\eta$ is the dynamic viscosity of the oil film, and $\bar{h}_{T}$ is the average clearance of the friction pairs.

Let us assume that the surface asperity height of the friction disk and separator plate are subject to Gaussian distribution of zero average value. Then, the relationship between the average clearance of friction pairs $\bar{h}_{T}$ and oil film thickness $h$ can be described as [17]

$$
\frac{\mathrm{d} \bar{h}_{T}}{\mathrm{~d} t}=\left\{0.5\left[1+\operatorname{erf}\left(\frac{h}{\sqrt{2} \sigma}\right)\right]\right\} \frac{\mathrm{d} h}{\mathrm{~d} t}
$$

Assume that

$$
g(h)=0.5\left[1+\operatorname{erf}\left(\frac{h}{\sqrt{2} \sigma}\right)\right],
$$

where $\sigma$ is the RMS roughness of the friction pairs and erf is the Gaussian error function. 


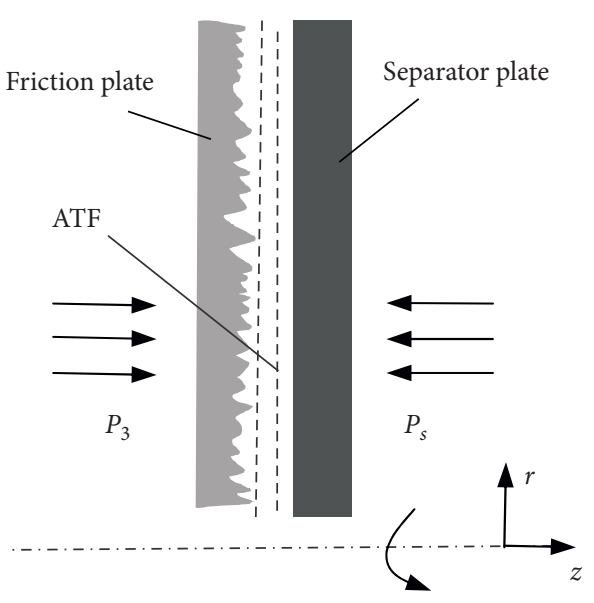

Figure 1: Physical model of wet clutch engagement.

On combination of the oil film boundary condition at the inner and outer diameters of the friction pairs, the oil film pressure in the radial distribution can be obtained as [17]

$$
P_{h}(r)=\frac{3 \eta}{\varphi_{r}\left(h^{3}+12 \Phi d\right)}\left[r^{2}+\frac{b^{2}-a^{2}}{2 \ln (a / b)} \ln \frac{r}{b}-b^{2}\right] g(h) \frac{\mathrm{d} h}{\mathrm{~d} t}
$$

2.2. Model of Asperity Contact Pressure. Let us assume that the surface asperity heights of the friction pairs are subject to Gaussian distribution combined with G-W elastic contact model. Then, the real contact area $A c$ between the asperities of the friction pairs in the wet clutch is obtained by $[18,19]$

$$
A_{c}=\pi \lambda \gamma \sigma\left[\frac{1}{\sqrt{2 \pi}} e^{-(h / \sqrt{2} \sigma)^{2}}+\frac{h}{\sigma}(g(h)-1)\right],
$$

where $\lambda$ is the asperity density and $\gamma$ is the asperity tip radius.

Therefore, the asperity contact pressure of friction pairs in the wet clutch $P_{c}$ is expressed by

$$
P_{c}=E \delta,
$$

where $E$ is the equivalent elasticity modulus of friction pairs and $\delta$ is the real contact area ratio $\left(\delta=A_{c} / A_{n}\right)$, which is used to characterize the relationship between the real contact area and the nominal contact area $\left(A_{n}\right)$ of the friction pairs.

2.3. Model of Applied Pressure. During wet clutch engagement, the applied pressure is not a fixed value but gradually reaches the set value in a short period of time controlled by the hydraulic system. The applied pressure acting on the friction pairs can be obtained by fitting the applied pressure test data [11].

$$
P_{\mathrm{s}}=P_{\mathrm{o}}\left(1-\exp \left(-\frac{t}{t_{\mathrm{s}}}\right)\right)
$$

where $P_{\mathrm{o}}$ is the set value of pressure and $t_{\mathrm{s}}$ is the hysteresis time of pressure.
2.4. Model of Dynamic Transmitted Torque. According to the engagement of the wet clutch, the applied pressure is successively carried by the oil film and asperities, and the force balance during wet clutch engagement can be obtained as

$$
\pi\left(b^{2}-a^{2}\right) P_{\mathrm{s}}=(1-\delta) \iint P_{h} \mathrm{~d} A+\delta \iint P_{c} \mathrm{~d} A,
$$

where $a$ and $b$ are the inner and outer radii of the friction pairs, respectively.

Owing to different load carriers in wet clutch engagement, the mechanism of transmitted torque is also transformed gradually from the viscous torque of oil film $T_{v}$ to the friction torque of asperities $T_{c}$. The torque can be obtained from the torque balance condition in wet clutch engagement by using

$$
T=(1-\delta) T_{v}+\delta T_{c},
$$

where

$$
\begin{aligned}
T_{v} & =\int_{0}^{2 \pi} \int_{a}^{b}(1-\delta)\left(\varphi_{f}-\varphi_{f s}\right) \frac{r^{3} \eta \omega_{r e l}}{h} \mathrm{~d} r \mathrm{~d} \theta, \\
T_{c} & =\int_{0}^{2 \pi} \int_{a}^{b} \delta f_{c} P_{c} r^{2} \mathrm{~d} r \mathrm{~d} \theta, \\
T & =I \cdot \frac{\mathrm{d} \omega_{r e l}}{\mathrm{~d} t},
\end{aligned}
$$

where $\varphi_{f}$ and $\varphi_{f s}$ are the factors given by Patir-Cheng $[20,21], \omega_{r e l}$ is the relative angular velocity between the separator plates and friction disks, and $f_{c}$ is the friction coefficient of the asperity contact.

\section{Numerical Simulations and Analysis}

The force and torque balance equations are solved via integration using the Runge-Kutta method to obtain the oil film thickness $h^{i}$ and relative angular velocity of the friction pairs $\omega_{r e l}^{i}$ for each time increment $i$. The step of numerical integration is $0.001 \mathrm{~s}$, and the iteration termination condition corresponds to the point at which the relative angular velocity between the separator plates and friction disks is less than $0.001 \mathrm{rad} / \mathrm{s}$. Then, the viscous torque of the oil film, friction torque of the asperities, and total torque transmitted by the wet clutch can be obtained using the oil film thickness and rate of relative angular velocity variation. In the simulation, it is assumed that the angular velocity of the separator plate is always zero, and the initial angular velocity of the friction disk is $\omega_{0}$. The friction disks gradually compress against the separator plates under the applied pressure, until the angular velocity of the friction disks satisfies the iterative termination condition. By this time, the engagement of the wet clutch is completed.

To facilitate analysis of the influence law of lubricant viscosity, friction lining permeability, equivalent elastic modulus of the friction pairs, and surface roughness RMS on response time of torque in the wet clutch, the pressure response time $\left(\Delta t_{P}\right)$ and torque response time $\left(\Delta t_{T}\right)$ are defined, as shown in Figure 2. Here, $\Delta t_{P}$ is defined as the 


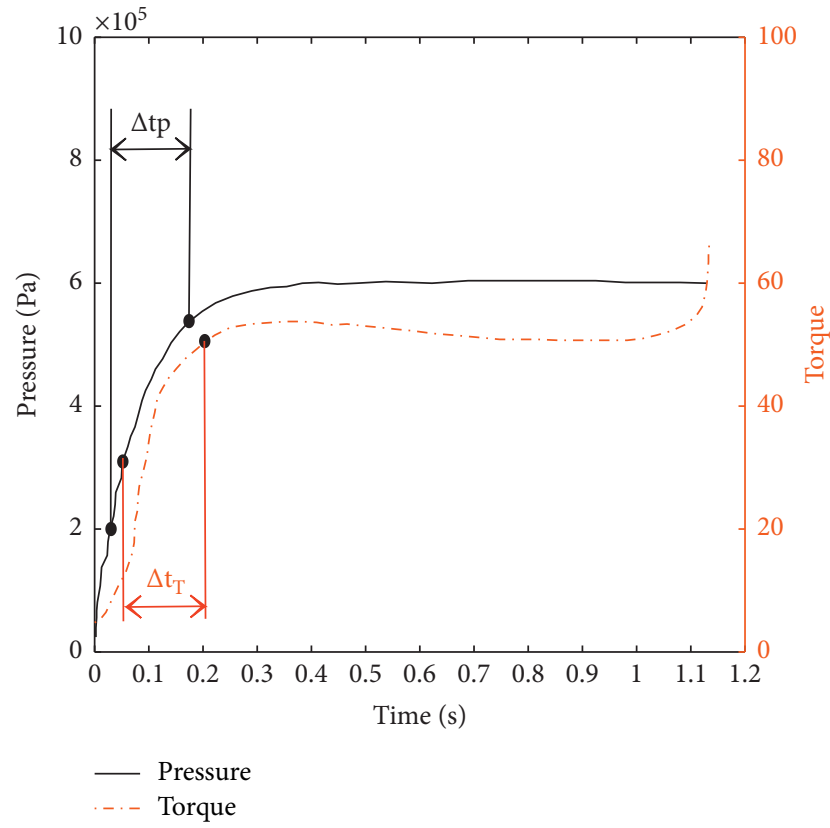

Figure 2: Definition of response time for pressure and torque.

time period when the value of applied pressure is between $10 \%$ and $90 \%$ of the stable value, and the torque response time $\Delta t_{T}$ is defined as the time period when the value of applied pressure is between $50 \%$ of the stable value and the torque is $90 \%$ of transmitted torque.

To investigate the effect of lubricant viscosity, friction lining permeability, equivalent elastic modulus of the friction pairs, and surface roughness RMS on response time of torque in the wet clutch, five groups of pressure hysteresis times are taken as $0.02 \mathrm{~s}, 0.04 \mathrm{~s}, 0.06 \mathrm{~s}, 0.08 \mathrm{~s}$, and $0.1 \mathrm{~s}$, respectively. The corresponding pressure response times are $0.044 \mathrm{~s}, 0.088 \mathrm{~s}, 0.132 \mathrm{~s}, 0.176 \mathrm{~s}$, and $0.22 \mathrm{~s}$ according to formula (6) and the definition of pressure response time. Then, the effect of pressure hysteresis time, lubricant viscosity, permeability of friction lining, equivalent elastic modulus of friction pairs, and surface roughness RMS on torque response time are studied, respectively, based on the dynamic torque model of the wet clutch. The initial conditions for the simulation are listed in Table 1.

3.1. Effect of Pressure Hysteresis Time. The effect of pressure hysteresis time $t_{s}$ on applied pressure $P_{s}$ and transmitted torque $T$ during wet clutch engagement is shown in Figure 3. This figure indicates that, by increasing the pressure hysteresis time, the applied pressure and transmitted torque take more time to reach stable values, and the response time of the applied pressure and transmitted torque are both extended. However, the change in pressure hysteresis time imposes only a minor influence on the stable value of the transmitted torque. Appropriately reducing the pressure hysteresis time can accelerate the response of the transmission torque, shorten the wet clutch engagement time, and increase the impact force of wet clutch engagement.
TABLE 1: Initial conditions for simulation.

\begin{tabular}{lc}
\hline Parameters & Value \\
\hline Inner radius of friction pairs, $a / \mathrm{m}$ & 0.064 \\
Outer radius of friction pairs, $b / \mathrm{m}$ & 0.085 \\
Friction lining thickness, $d / \mathrm{m}$ & 0.001 \\
Surface roughness, $\sigma / \mathrm{m}$ & $8.41 \times 10^{-6}$ \\
Friction material permeability, $\Phi / \mathrm{m}^{2}$ & $4 \times 10^{-12}$ \\
Equivalent elasticity modulus, $E / \mathrm{Pa}$ & $2.7 \times 10^{7}$ \\
Asperity density, $\lambda / \mathrm{m}^{2}$ & $7 \times 10^{7}$ \\
Asperity tip radius, $R / \mathrm{m}$ & $8 \times 10^{-4}$ \\
Initial film thickness, $h_{\mathrm{o}} / \mathrm{m}$ & $8.8 \times 10^{-5}$ \\
Lubricant viscosity, $\eta / \mathrm{Pa} \cdot \mathrm{s}$ & 0.0681 \\
Maximum applied pressure, $P_{\mathrm{o}} / \mathrm{Pa}$ & $6 \times 10^{5}$ \\
Initial angular velocity, $\omega_{\mathrm{o}} / \mathrm{rad} / \mathrm{s}$ & 1000 \\
Moment of inertia, $I / \mathrm{kg} \cdot \mathrm{m}^{2}$ & 0.56 \\
\hline
\end{tabular}

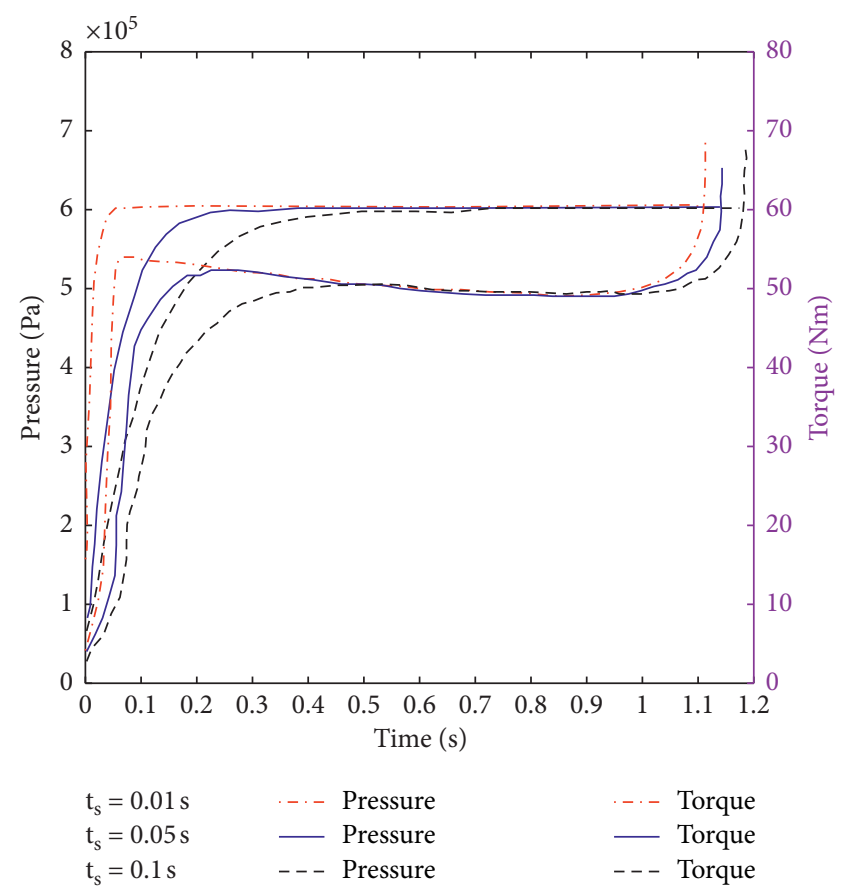

FIgURE 3: Effect of pressure hysteresis time on torque response time.

3.2. Effect of Lubricant Viscosity. It can be understood from the simulation results shown in Figure 4 that the pressure response time and the transmitted torque response time have a positive correlation, and the lubricant with a lower viscosity demonstrates more sensitivity of transmitted torque response time to pressure response time. In contrast, with the increase in lubricant viscosity, the sensitivity of transmitted torque response time to pressure response time reduces. This is owing to the resistance caused by squeezing oil film increasing with the increase in lubricant viscosity during the engagement of the wet clutch. Consequently, the duration for which the oil film remains between the separator plate and the friction disk increases. Further, the transmitting torque response time is insensitive to the 


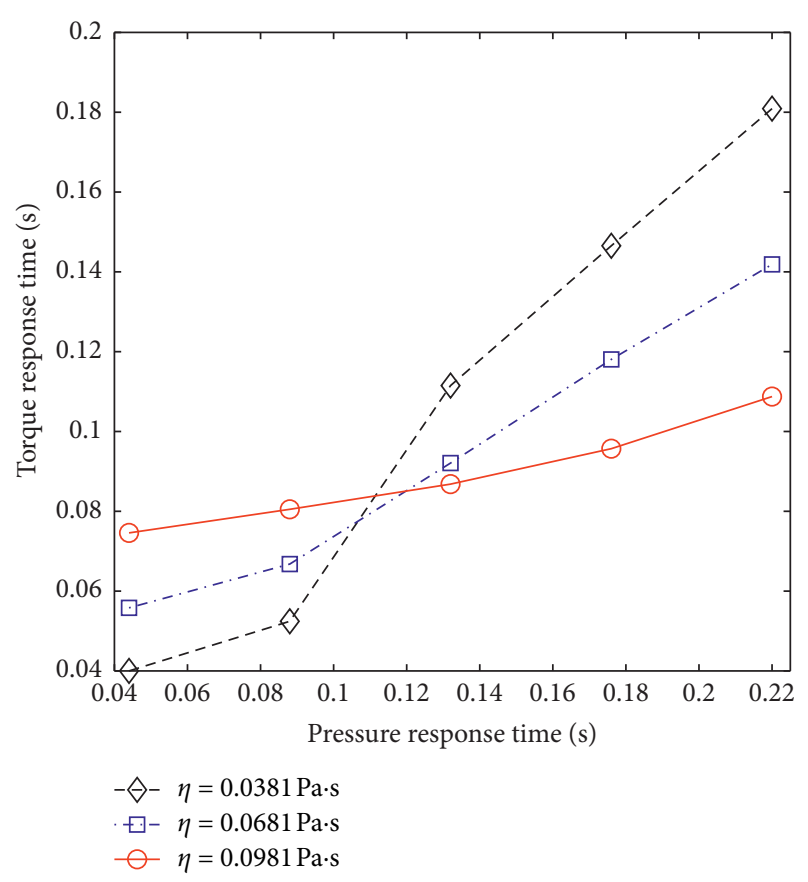

FIgURE 4: Effect of lubricant viscosities on torque response time.

change in pressure response time under high lubricant viscosity in wet clutch engagement and vice versa.

When the pressure response time is short, under the same pressure response time, as the viscosity of the lubricating oil is greater, the torque response time is longer, the transmission torque rises more smoothly, and the level of jerk of the wet clutch engagement is smaller. This is because, in the squeeze stage, the greater the viscosity of the lubricating oil, the greater the viscous resistance of the lubricating oil penetrating into the friction lining or being squeezed out along the friction surface, so the longer the squeeze stage lasts, the slower the transmitted torque response is.

Conversely, when the pressure response time is relatively long, under the same pressure response time, as the viscosity of the lubricating oil is greater, the torque response time is shorter, the transmission torque rises faster, and the level of jerk of the wet clutch engagement is greater. When the pressure response time is relatively long, as the viscosity of the lubricating oil changes, the flow inertia of the cooling lubricating oil has less influence, and the centrifugal force on the cooling lubricating oil in the separation gap is the dominant factor. Therefore, when designing a wet clutch, pressure response time and lubricating oil viscosity must be considered at the same time.

3.3. Effect of Friction Lining Permeability. Figure 5 demonstrates the variation in torque response time due to different friction lining permeability. It is found that, with the increase in the permeability of friction lining, torque response time under the same pressure response time is reduced. This is because the higher the permeability of the friction lining is, the easier the lubricant permeates into the porous structure

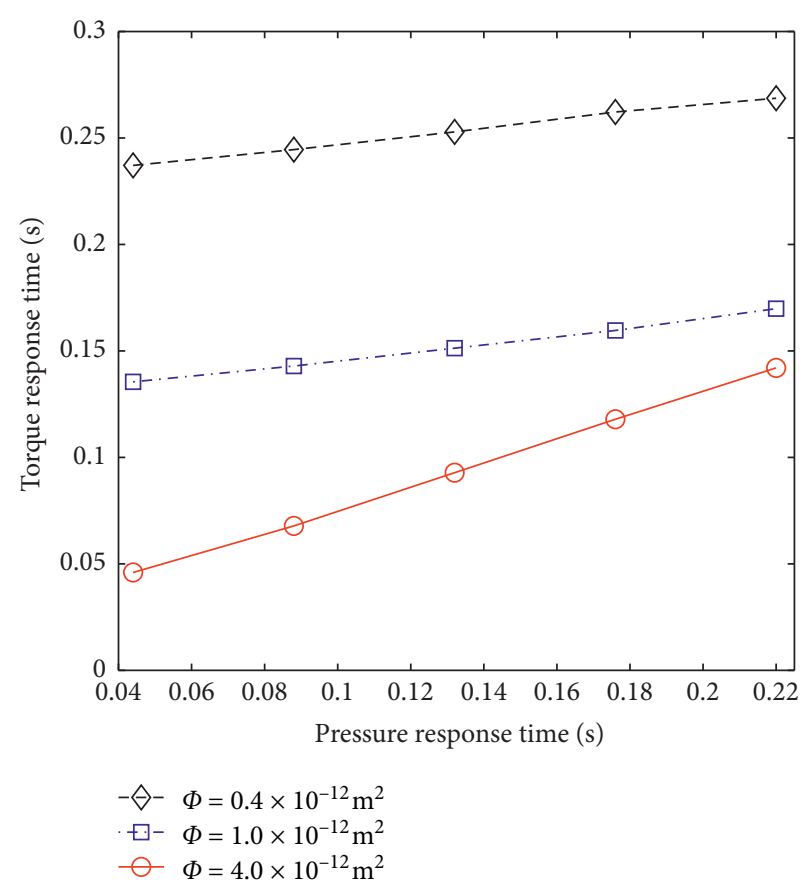

FIGURE 5: Effect of friction lining permeability on torque response time.

of the friction lining. As a result, the duration of the fluid squeezing stage is shortened, and the torque response time is reduced. The greater the permeability of the friction lining, the faster the torque response time under the same pressure response time, which indicates that the faster the transmitted torque rises, the greater the level of jerk of the wet clutch engagement is.

Further, the higher the permeability of the friction lining is, the more sensitive the torque response time to pressure response time is and vice versa. This is because the hydrodynamic pressure effect is easily formed between the friction pairs when the permeability of friction linings is low, which weakens the effect of pressure response time variation on the transmitted torque response.

3.4. Effect of Equivalent Elastic Modulus. The effect of different equivalent elastic modulus on torque response time is illustrated in Figure 6. It can be seen from Figure 6 that, with the increase in equivalent elastic modulus of friction pairs, torque response time is reduced slightly under the same pressure response time. With a fixed elastic modulus, torque response time is increased with the increase in pressure response time. This is because, in the same pressure response time, the larger the equivalent elastic modulus is, the larger the bearing force generated by the same deformation and the larger friction torque of asperities will be. Meanwhile, the thickness of the oil film between friction pairs becomes larger when the equivalent elastic modulus increases, so the viscous torque of oil film becomes smaller, which results in a faster response of transmitted torque. As the equivalent elastic modulus increases, the torque response time 


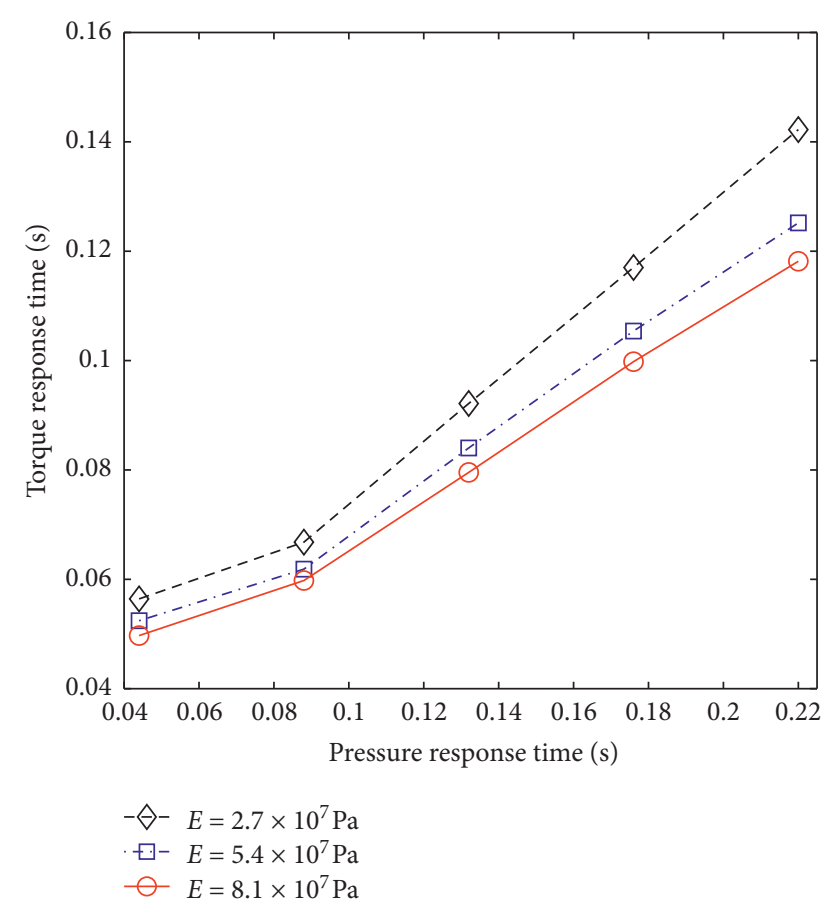

Figure 6: Effect of equivalent elastic modulus on torque response time.

decreases slightly under the same pressure response time, indicating that the faster the transmitted torque rises, the greater the level of jerk of the wet clutch engagement is.

3.5. Effect of Surface Combined Roughness RMS. It can be comprehended from Figure 7 that, by increasing the surface combined roughness RMS of friction pairs, the torque response time corresponding to the same pressure response time is increased. The reason for this is that, with the increase of surface combined roughness RMS of friction pairs, the contact of asperities proceeds in advance, the force supported by oil film drops, the shear flow factor is reduced, the number of the asperities in contact becomes less, and the friction torque of asperities is reduced; thus the transmitted torque response time increases. As the surface combined roughness RMS increases, the torque response time is slightly longer under the same pressure response time, the transmitted torque rises slowly, and the level of jerk of the wet clutch engagement is smaller. Moreover, the higher the surface combined roughness RMS of friction pairs is, the more sensitive the response of transmitted torque to the change of pressure response will be.

\section{Test Verification}

To validate the simulation results, the response characteristics of transmitted torque of wet clutch are tested using the wet clutch comprehensive performance test rig, and the specifications and materials of the friction pairs used in the test are consistent with what was used in the numerical simulation, which is shown in Figure 8. In the test, the

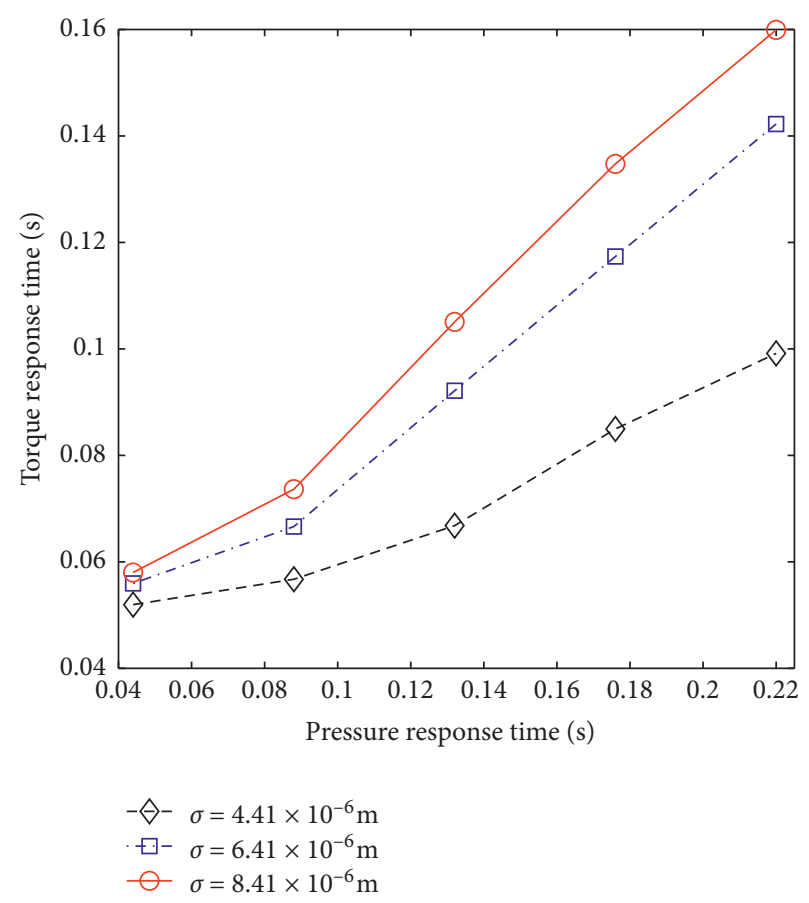

FIGURE 7: Effect of surface combined roughness RMS on torque response time.

separator plates were mounted on the outer hub, and the friction disks were mounted on the inner hub of clutch, following which the outer hub was fixed by the torque meter such that the separator plates were fixed. Furthermore, the inner hub of clutch was connected with an inertia flywheel driven by the motor to determine the rotation of friction disks. The working principle of the bench is as follows: First, the speed of active end is set to a constant value, and then the IPC (Industrial Personal Computer) controls the hydraulic system according to the set pressure curve and applies the engaging pressure to the friction pair of the wet clutch until the displacement of the friction plate of the drive end is zero. During the entire test process, the change regulation of transmitted torque and pressure in engagement were measured and recorded at a $1 \mathrm{kHz}$ sampling frequency using the test system in real time, as shown in Figure 9.

To ensure the comparability between the test and simulation results, PID parameters of clutch hydraulic control system on the test rig were adjusted repeatedly before the measurement to understand the control of different pressure response time, which includes $0.044 \mathrm{~s}, 0.088 \mathrm{~s}, 0.132 \mathrm{~s}$, $0.176 \mathrm{~s}$, and $0.22 \mathrm{~s}$ in each work condition of the test.

Due to the limitations of test conditions, only the influence law of lubricant viscosity and surface combined roughness RMS of friction disk on the response characteristics of transmitted torque for wet clutch was tested and verified. To investigate the effect of lubricant viscosity, the test was performed to assess the transmitted torque response time with respect to different pressure response times of the wet clutch with lubricant temperatures of $40^{\circ} \mathrm{C}, 80^{\circ} \mathrm{C}$, and $110^{\circ} \mathrm{C}$. The comparison between test results and simulation results is shown in Figure 10. It can be seen from the figure 

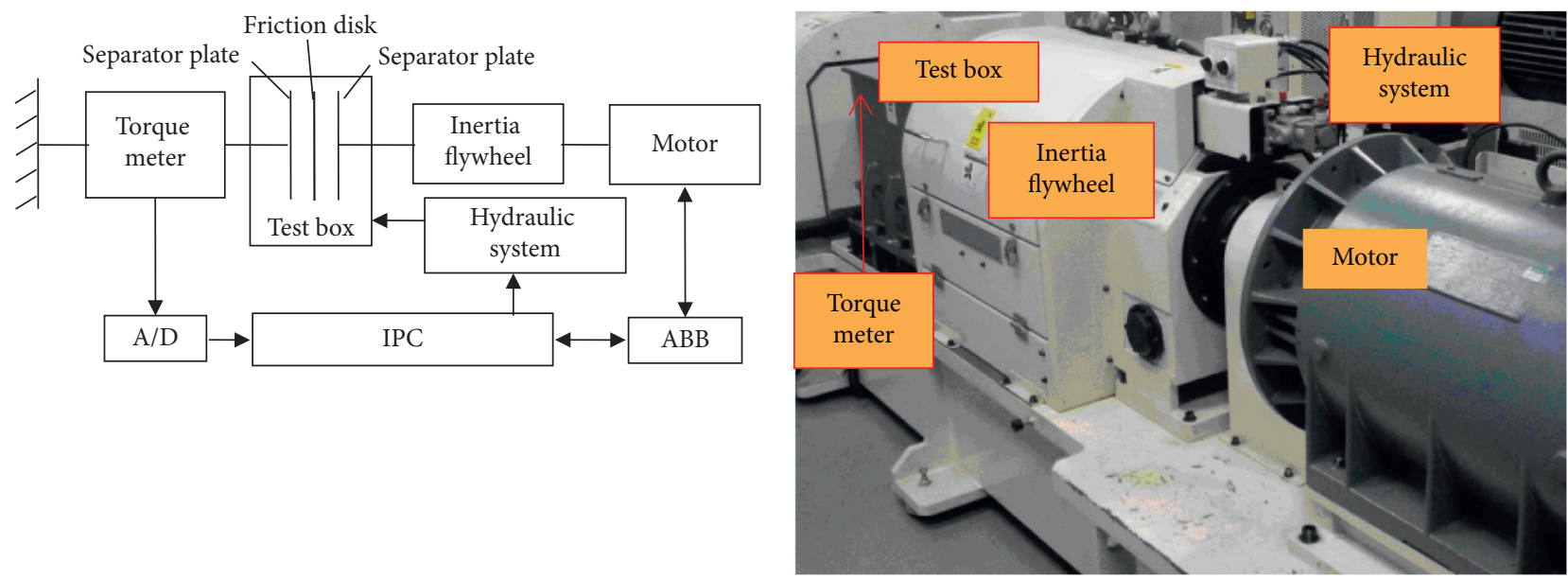

(a)

(b)

Figure 8: Wet clutch comprehensive performance test rig. (a) Test rig principle. (b) Test rig picture.

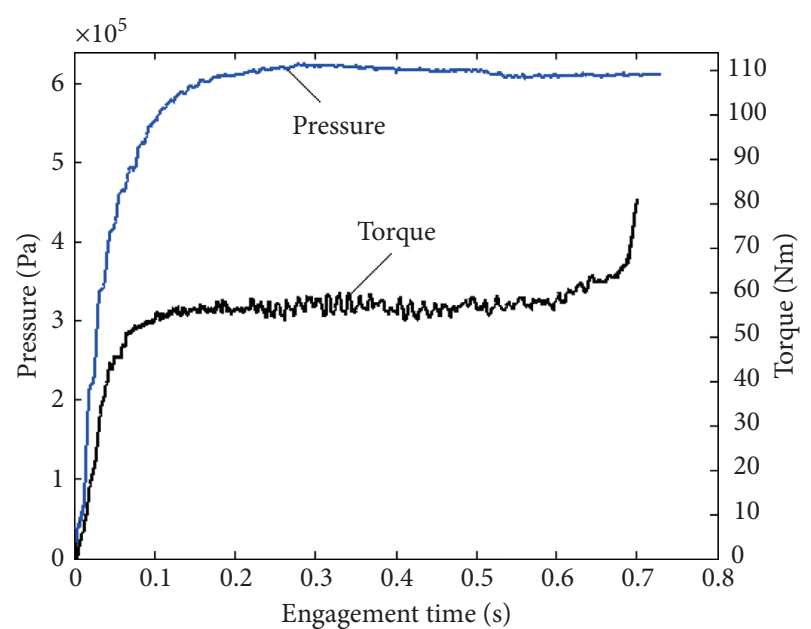

Figure 9: Response characteristics of torque for wet clutch.

that the simulation results are highly consistent with the test results, but the response time during the test is longer than that during the simulation. This is mainly due to the flow whose lubricant viscosity decreases with the increase of shear stress, that is, shear thinning flow.

Moreover, the test was performed to assess the transmitting torque response time under different pressure response time with new friction disk, new friction disk in running-in period, and worn friction disk with lubricant temperature of $40^{\circ} \mathrm{C}$ to evaluate the effect of surface combined roughness RMS on response time of transmitting torque; the results are shown in Figure 11. The effect of test and simulation roughness RMS on the response time of the transmitted torque is shown in Figure 11. It can be seen from

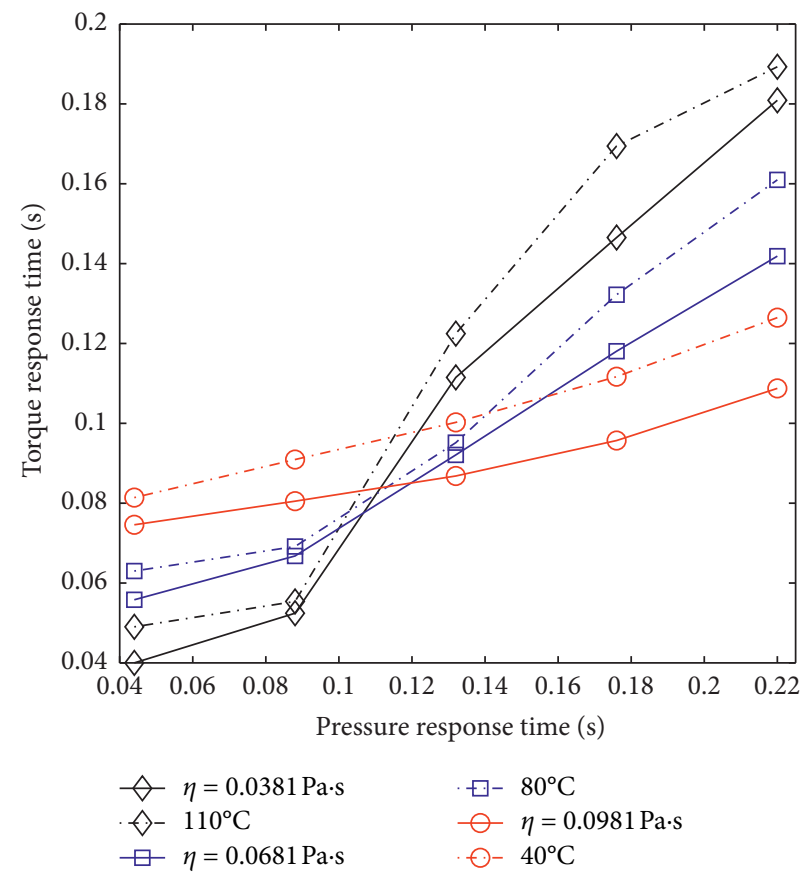

Figure 10: Test results of effect of lubricant viscosities on torque response time.

the figure that the test results and the simulation results have good consistency, but there are also certain deviations. This is mainly because the friction disk used has a smaller range when sampling, but the overall roughness shown by the whole is deviated from the simulation roughness.

Through the experiment of viscosity and roughness, it is proved that the simulation analysis model in this paper is 


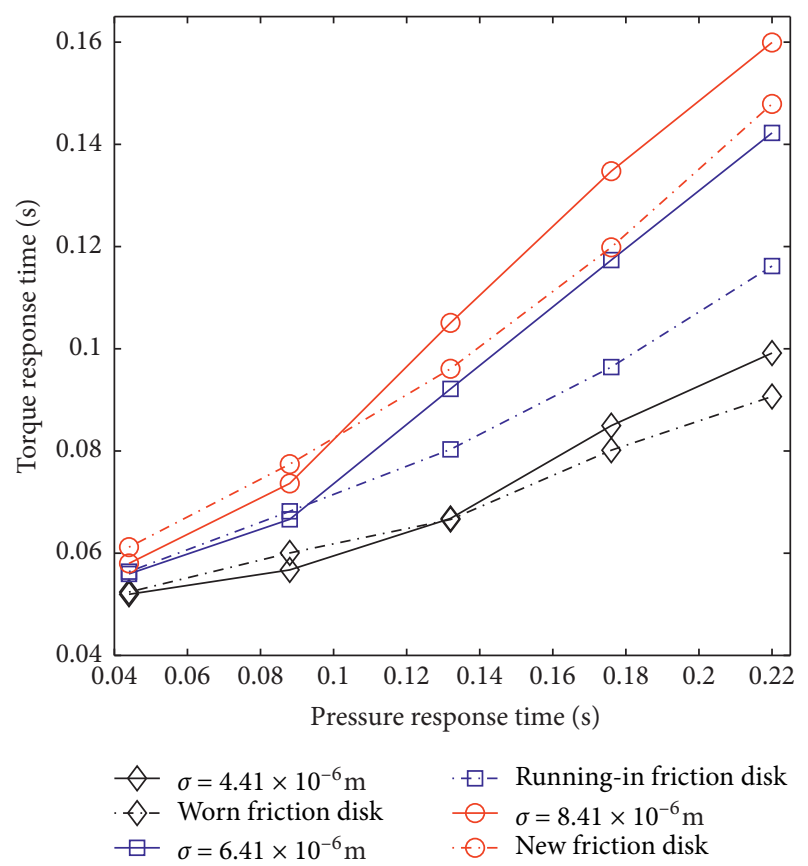

Figure 11: Test results of effect of surface roughness on torque response time.

reliable and can be used to analyze the change law of the dynamic transmitted torque response characteristics of the wet clutch.

\section{Conclusions}

For the engagement of the wet clutch, four models of the oil film pressure, the asperity contact pressure, the applied pressure, and the dynamic transmitted torque model are established. Based on the mathematical model established, the simulation analysis method was used to study the influence of the pressure hysteresis time, lubricant viscosity, friction lining permeability, friction pair equivalent elastic modulus, and surface combined roughness RMS on the dynamic transmitted torque response characteristics during the wet clutch engagement. Further, a wet clutch comprehensive performance test bench was used to verify the law of the influence of lubricant viscosity and surface combined roughness RMS on the transmitted torque response time and to verify the validity of the established mathematical model. The result shows the following:

(1) The longer the pressure hysteresis time, the more delayed the response of transmitted torque and the smaller the level of jerk of the wet clutch engagement.

(2) The lower the lubricant viscosity is, the more sensitive the transmitted torque response is to the pressure response time; and the pressure response time has a great influence on the transmitted torque response time of different lubricant viscosities.

(3) The greater the permeability of the friction lining is, the faster the transmitted torque response is, the more sensitive it is to pressure response changes, the shorter the time for the wet clutch to engage is, and the greater the level of jerk is.

(4) The smaller the equivalent elastic modulus is, the slower the transmitted torque response is, the more sensitive it is to pressure response changes, the longer the time for the wet clutch to engage is, and the smaller the level of jerk is.

(5) The greater the surface combined roughness RMS is, the slower the transmitted torque response is, the more sensitive it is to pressure response changes is, and the smaller the level of jerk of wet clutch engagement is.

(6) Due to the limitations of test conditions, only the influence of lubricant viscosity and surface combined roughness RMS of friction disk on the transmitted torque response characteristics for wet clutch was tested and verified. This verifies the correctness of the simulation analysis and shows that the simulation analysis model in this paper is reliable; and it can be used to analyze the change law of the dynamic transmitted torque response characteristics of the wet clutch, and further experimental research on other influencing factors can be carried out in the future.

\section{Data Availability}

The data used to support the findings of this study are included within the article.

\section{Conflicts of Interest}

The authors declare that they have no conflicts of interest.

\section{Acknowledgments}

This paper was supported by Chongqing Research Program of Basic Research and Frontier Technology (no. cstc2017jcyjAX0143), China Postdoctoral Science Foundation (no. 2020M681808), and the Postdoctoral Research Preferred Fund Project of Zhejiang Province (no. ZJ2020080).

\section{References}

[1] X. C. Liu, Z. G. Zhang, X. H. Shi et al., "Effect of engagement pressure on engagement characteristics of wet clutch," Journal of Chongqing University of Technology (Natural Science), vol. 4, no. 1, pp. 7-11, 2015.

[2] Y. Yang, C. L. Robert, and F. Tamotsu, "Prediction of torque response during the engagement of wet friction clutch," SAE Technical Paper, Warrendale, PA, USA, 981097, 1998.

[3] H. Gao, G. C. Barber, and M. Shillor, "Numerical simulation of engagement of a wet clutch with skewed surface roughness," Journal of Tribology, vol. 124, no. 2, pp. 305-312, 2002.

[4] J. Y. Jang, M. M. Khonsari, and R. Maki, "Three-dimensional thermohydrodynamic analysis of a wet clutch with consideration of grooved friction surfaces," Journal of Tribology, vol. 133, no. 1, Article ID 011703, 2011. 
[5] L. Yu, B. Ma, M. Chen, H. Li, J. Liu, and L. Zheng, "Numerical and experimental studies on the characteristics of friction torque based on wet paper-based clutches," Tribology International, vol. 131, no. 1, pp. 541-551, 2018.

[6] L. C. Yang, Simulation Study on Torque Characteristics of Multi-Plate Wet Clutch, Jilin University, Changchun, China, 2015, in Chinese.

[7] H. Chen, "The effect of wet clutch engagement oil pressure on speed and torque," Equipment Management and Maintenance, vol. 13, no. 1, pp. 53-55, 2018.

[8] M. Chen, B. Ma, G. Li et al., "Study on torque characteristics of multi-plate wet clutches during engagement," Journal of Huazhong University of Science and Technology (Natural Science Edition), vol. 42, no. 5, pp. 34-39, 2014.

[9] M. Miyagawa, M. Ogawa, Y. Okano, H. Hara, S. Sasaki, and K. Okui, "Numerical simulation of temperature and torque curve of multidisk wet clutch with radial and circumferential grooves," Tribology Online, vol. 4, no. 1, pp. 17-21, 2009.

[10] M. K. Thakur and C. Sarkar, "Investigation of different groove profile effects on torque transmission in shear mode magnetorheological clutch: numerical simulation and experimental study," Journal of Tribology, vol. 143, no. 9, pp. 1-10, 2020.

[11] L. Yu, B. Ma, M. Chen et al., "Influence of the temperature of lubricating oil on the friction torque of cu-based wet clutch," Journal of Mechanical Engineering, vol. 56, no. 20, pp. 155-163, 2020.

[12] B. Depraetere, G. Pinte, W. Symens, and J. Swevers, "A twolevel iterative learning control scheme for the engagement of wet clutches," Mechatronics, vol. 21, no. 3, pp. 501-508, 2011.

[13] J. Park and S. Choi, "Adaptive control method of clutch torque during clutch slip engagement," in Proceedings fo the 2020 American Control Conference (ACC), July 2020.

[14] Z. Zhang, X. Zhou, L. Shen, and Y.-J. Li, "Simulation and experiment on dynamic engagement characteristics of wet clutch," China Journal of Highway and Transport, vol. 23, no. 3, pp. 115-120, 2010.

[15] P. Zagrodzki and S. A. Truncone, "Generation of hot spots in a wet multidisk clutch during short-term engagement," Wear, vol. 254, no. 5-6, pp. 474-491, 2003.

[16] F. Meng, Q. J. Wang, D. Hua, and S. Liu, "A simple method to calculate contact factor used in average flflow model," Journal of Tribology, vol. 132, no. 2, pp. 483-485, 2010.

[17] Y. Chen, Research on Temperature Characteristics and Thermal Failure of Wet Multi-Disk Clutch, Chongqing University Technology, Chongqing, China, 2019, in Chinese.

[18] Z. Y. Li, "Modeling and simulation of dual clutch joint start control of wet DCT," Mechanical Transmission, vol. 43, no. 1, pp. 109-113, 2019.

[19] Q. L. Wang, "Research on transient characteristic of stress fifield of the friction pair during soft start-up process of hydro-viscous drive," Mechanical Transmission, vol. 43, pp. 32-37, 2019.

[20] N. Patir and H. S. Cheng, "Application of average flflow model to lubrication between rough sliding surfaces," Journal of Tribology, vol. 101, no. 2, pp. 229-230, 1979.

[21] X. B. Shang, Theoretical Analysis and Experimental Study on Engagement Process of Wet Clutch, Zhejiang University, Hangzhou, China, 2019, in Chinese. 